\title{
Cerebral Aneurysm Sac Growth as the Etiology of Recurrence after Successful Coil Embolization
}

\author{
David M. Hasan, MD¹, Alexander I. Nadareyshvili, PhD², Anna L. Hoppe, BS², Kelly B. \\ Mahaney, MD ${ }^{1}$, David K. Kung, MD ${ }^{1}$, and Madhavan L. Raghavan, PhD $^{2}$ \\ ${ }^{1}$ Department of Neurosurgery, Carver College of Medicine, University of lowa, lowa City, lowa \\ ${ }^{2}$ Department of Biomedical Engineering, College of Engineering, University of lowa, lowa City, \\ lowa
}

\section{Abstract}

Background and Purpose-Coil compaction is thought to be the main mechanism for recurrence in cerebral aneurysms with previously successful coil embolization. We hypothesize that sac growth may be equally or more important. The objective is to study the relative roles of coil compaction and sac growth as explanations for aneurysm recurrence requiring re-treatment in a study population using quantitative three-dimensional image processing methods.

Methods-From July 2009 to December 2010, 175 aneurysms were coiled at the University of Iowa Hospitals and Clinics. Eight aneurysms had major recurrence requiring re-treatment (4.4 to 12.1 months between procedures; mean 7.2 months). The 3-dimensional structures of the vessel and coil mass were reconstructed using rotational angiography data scanned before and after both initial coil embolization and retreatment. Changes in the sac and coil mass over time were visualized using model registration techniques and quantified using volume calculations.

Results-All eight coiled aneurysms with major recurrence had significant aneurysm sac growth (15-102\% increase in volume), independent of change in coil volume. Five aneurysms with major recurrence had sufficient data for assessment of coil compaction. The Coil mass volume decreased in one aneurysm (12\% compaction by volume), did not change significantly in one aneurysm (increased by $1 \%$ ) and significantly increased in three aneurysms $(8 \%, 21 \%$, and $25 \%$ ) between the first treatment and before the second treatment.

Conclusion-In this study population, aneurysm sac growth, not coil compaction was the primary mechanism associated with recurrence following initial coil embolization.

\section{Keywords}

cerebral aneurysm; recurrence; image analysis; sac growth; coil compaction

\section{Introduction}

Recurrence remains a considerable challenge following coil embolization of aneurysms.

Recurrence rates of up to $34 \%$, with major recurrence rates of up to $21 \%$ have been reported. ${ }^{1-3}$ Yet the mechanisms underlying recurrence are poorly understood. Whereas coil compaction remains the presumptive mechanism, evidence to support that premise is mostly

Corresponding Author: Madhavan L. Raghavan, 1136 Seamans Center, Department of Biomedical Engineering, University of Iowa, Iowa City, IA 52242, Ph: 319-335 5704, Fax: 319-335 5631, ml-raghavan@uiowa.edu.

Conflict of Interest/Disclosure:

The authors have no conflicts of interest to disclose. 
observational and qualitative. ${ }^{4-6}$ On the other hand, sac growth is considered only peripherally as a mechanism for recurrence ${ }^{7-9}$. We submit otherwise. Prior studies of aneurysm recurrence have been confined to qualitative observations from two-dimensional angiographic data, which may not allow for accurate discrimination of aneurysm sac growth from coil compaction, as the coil mass may appear smaller, in relation to an aneurysm sac which has grown. But rigorous quantitative studies on the evolution of the aneurysm sac and/or coil mass are lacking. The objective of this study was to use rigorous three-

dimensional image processing methods to assess the association of coil compaction and sac growth with recurrence in a study population of intracranial aneurysm patients treated with endovascular coils.

\section{Methods}

Between July 2009 and December 2010, 175 intracranial aneurysm patients were treated with coil embolization at the University of Iowa Hospitals and Clinics. Eight patients presented with major recurrence at followup and were treated with additional coiling (4.4 to 12.1 months between procedures; mean 7.2 months). The study was conducted using threedimensional rotational angiography (3DRA) data collected retrospectively from this cohort of eight patients that had recurrence. Prior Institutional Review Board approval (IRB\# 201007774) was obtained. Fine-cut cross-sectional images of a 3D acquisition run (using syngoInPace 3D, Siemens) were obtained from study subjects at four time points (pre-first treatment, post-first treatment, pre-second treatment and post-second treatment). The 3D models of aneurysm sac and branch vessels were reconstructed from the pre-first treatment 3DRA data by employing a vessel segmentation algorithm within image processing utility, 3D Slicer. For the 3D reconstruction of the coil mass structure from the following three time points, the bone scan data was utilized because its clarity was significantly better than the subtracted angiographic data for the coil region. The branch vessels and residual regions within sac were reconstructed from the subtracted angiographic data for the respective time points. The centerlines of reconstructed 3D models of the non-diseased vessels within each dataset were used as landmarks for alignment of structures from all four time points within a given subject (i.e., registration). Centerlines were computed using a module available within 3D Slicer that was developed based on a technique reported by Ford et al. ${ }^{10}$ The pre-first treatment aneurysm sac was then isolated from its contiguous vessels using a cutting plane subjectively chosen by adjudication with a clinical investigator. Since all models have been registered in 3D space, this same cutting plane was used to isolate the sac for the latter three time points as well. The volumes for the following structures were then computed: 1) aneurysm sac volume at initial presentation ( $\left.\boldsymbol{V}_{\mathrm{SI}}\right)$ from pre-first treatment scan; 2 ) aneurysm sac volume at follow-up $\left(\boldsymbol{V}_{\mathrm{SF}}\right)$ by summing the coil mass volume with its residual volume in the post-second treatment scan; 3$)$ initial coil mass volume $\left(\boldsymbol{V}_{\mathrm{CI}}\right)$ from the post-first treatment scan; and 4) follow-up coil mass volume $\left(\boldsymbol{V}_{\mathrm{CF}}\right)$ from the pre-second treatment scan. From these, the sac volume growth $\left(\boldsymbol{V}_{\mathrm{SG}}=\boldsymbol{V}_{\mathrm{SF}}-\boldsymbol{V}_{\mathrm{SI}}\right), \%$ sac growth $\left(\% \boldsymbol{V}_{\mathrm{SG}}=\boldsymbol{V}_{\mathrm{SG}} /\right.$ $\left.\boldsymbol{V}_{\mathrm{SI}}\right)$, coil mass volume growth $\left(\boldsymbol{V}_{\mathrm{CG}}=\boldsymbol{V}_{\mathrm{CF}}-\boldsymbol{V}_{\mathrm{CI}}\right)$ and $\%$ coil mass volume growth $\left(\% \boldsymbol{V}_{\mathrm{CG}}\right.$ $=V_{\mathrm{CG}} / \boldsymbol{V}_{\mathrm{CI}}$ ) were calculated. Sac growth will be indicated by $\boldsymbol{V}_{\mathrm{SG}}>0$ and coil mass compaction will be indicated by $\boldsymbol{V}_{\mathrm{CG}}<0$. Paired t-tests comparing $\boldsymbol{V}_{\mathrm{SI}}$ with $\boldsymbol{V}_{\mathrm{SF}}$ and $\boldsymbol{V}_{\mathrm{CI}}$ with $\boldsymbol{V}_{\mathrm{CF}}$ were conducted to test our hypotheses (statistical significance at $\mathrm{p}<0.05$ ). In order to assess how sensitive the volume calculations are to user subjectivity, a second investigator performed all image analyses and volume calculations blinded from the first investigator. The resulting volumes, $\boldsymbol{V}_{\mathrm{SI}}, \boldsymbol{V}_{\mathrm{SF}}, \boldsymbol{V}_{\mathrm{CI}}$, and $\boldsymbol{V}_{\mathrm{CF}}$ were compared to quantify the consistency in the measurements. 


\section{Results}

\section{Demographic and procedural information on study subjects is provided in Table 1}

The baseline and subtraction angiographic 3DRA data needed for sac growth calculations was available in all eight study subjects. However, image data needed for coil growth calculations was only available in five of these eight study subjects. Figure 1 illustrates visually the morphological change in aneurysm sac and the coil mass in the follow-up period for study subjects, respectively. Sac growth was noted in 8 (of 8) study subjects while coil compaction was noted in just 1 study subject (out of 5). Indeed, in 3 (of 5) subjects, the coil mass was found to grow, not compact. Quantitative analysis of volumes is consistent with this visual observation. Figure 2 shows subject-specific initial and followup volumes, and the change in these volumes. Paired student-t tests showed that the aneurysm sac volume at followup was larger than at initial presentation with statistical significance (mean $\pm \mathrm{SD}$ of paired differences, $\boldsymbol{V}_{\mathrm{SG}}=224 \pm 196 \mathrm{cu}$. $\left.\mathrm{mm} ; \% \boldsymbol{V}_{\mathrm{SG}}=49 \pm 31 \% ; \mathrm{p}=0.014 ; \mathrm{N}=8\right)$ while coil mass volume was not $\left(\boldsymbol{V}_{\mathrm{CG}}=-2 \pm 152 \mathrm{cu}\right.$. $\left.\mathrm{mm} ; \% \boldsymbol{V}_{\mathrm{CG}}=7 \pm 14 \% ; \mathrm{p}=0.98 ; \mathrm{N}=5\right)$. User sensitivity studies suggest a strong agreement between the users for all volumes although some sensitivity does exist. While results from the primary investigator's calculations are presented above, those of the secondary investigator are similar for sac growth $\left(\boldsymbol{V}_{\mathrm{SG}}=\right.$ $\left.213 \pm 192 \mathrm{cu} . \mathrm{mm} ; \% \boldsymbol{V}_{\mathrm{SG}}=51 \pm 37 \% ; \mathrm{p}=0.016 ; \mathrm{N}=8\right)$ and coil compaction $\left(\boldsymbol{V}_{\mathrm{CG}}=0.2 \pm 122\right.$ cu. $\mathrm{mm} ; \% \boldsymbol{V}_{\mathrm{CG}}=8 \pm 16 \% ; \mathrm{p}=0.997 ; \mathrm{N}=5$ ). Bland Altman plots did not reveal any bias in the differences between users.

\section{Discussion}

In this study population, coil mass compaction was not consistently associated with aneurysm recurrence. Coil compaction (see Figure 2B) occurred in one patient (subject \#7; $12 \%$ decrease in volume) and negligible coil growth in another (subject \#6;1\% increase in volume). These two patients were treated with bare platinum coils. Coil mass growth occurred in three patients ( 8 to $20 \%$ increase in volume), all of whom were treated with hydrocoils. On the other hand, sac growth occurred in all 8 cases (15 to $102 \%$ increase in volume; Figure 2A) with statistical significance. Visually, it is apparent that in these cases, sac growth may have merely shifted the coil mass deeper into the enlarged sac facilitating recanalization closer to the neck (see Figure 1A). The shift in coil mass when small may seem like a compaction on angiograms especially when scaling and orientations are not maintained precisely consistent between different time points (see Figure 1B). But in this study population, coil compaction was rare.

\section{Limitation of the current study}

The small study sample warrants some caution. It is conceivable that this study is not representative of the patient population at large. Future studies would benefit from larger study populations and longer follow-up to determine whether aneurysm sac growth remains the main cause of aneurysm recurrence over longer periods of time following treatment. Additionally, differing mechanisms of recurrence may be present in ruptured aneurysms versus unruptured aneurysms. This study is not powered to assess such differences. Investigator subjectivity in calculations is not entirely negligible and neither is the scope for error from image artifacts, but they are unlikely to impact the overall findings of this study.

\section{Conclusion}

The findings are consistent with our hypothesis that aneurysm sac growth is an important mechanism for recurrence following initial complete or near-complete obliteration of the sac using coil embolization. There was little evidence to support coil compaction as a consistent 
mechanism in this population. If validated by future studies, this finding suggests that perhaps a growing aneurysm is better managed with surgical clipping.

\section{Acknowledgments}

The findings of this study have not been presented, submitted, or published elsewhere in whole or in part.

Funding Sources:

This study was supported in part by funding from the National Institutes of Health (\#HL083475).

\section{References}

1. Murayama Y, Nien YL, Duckwiler G, Gobin YP, Jahan R, Frazee J, et al. Guglielmi detachable coil embolization of cerebral aneurysms: 11 years' experience. J Neurosurg. 2003; 98:959-966. [PubMed: 12744354]

2. Raymond J, Guilbert F, Weill A, Georganos SA, Juravsky L, Lambert A, et al. Long-term angiographic recurrences after selective endovascular treatment of aneurysms with detachable coils. Stroke. 2003; 34:1398-403. [PubMed: 12775880]

3. Molyneux A. International Subarachnoid Aneurysm Trial (ISAT) Collaborative group. International subarachnoid aneurysm trial (ISAT) of neurosurgical clipping versus endovascular coiling in 2143 patients with ruptured intracranial aneurysms: a randomized trial. Lancet Neurol. 2002; 360:12671274.

4. Byrne J, Sohn M, Molyneux A. Five-year experience in using coil embolization for ruptured intracranial aneurysms: outcomes and incidence of late rebleeding. J Neurosurg. 1999; 90:656-663. [PubMed: 10193610]

5. Kang HS, Han MH, Kwon B, Kwon OK, Kim SH. Repeat endovascular treatment in postembolization recurrent intracranial aneurysms. Neurosurgery. 2006; 58:60-70. [PubMed: 16385330]

6. Sluzewski M, Van Rooij WJ, Slob MJ, Bescos JO, Slump CH, Wijnalda D. Relation between aneurysm volume, packing, and compaction in 145 aneurysms treated with coils. Radiology. 2004; 231:653-658. [PubMed: 15118115]

7. Bavinzski G, Talazoglu V, Killer M, Richling B, Gruber A, Gross C, et al. Gross and microscopic histopathological findings in aneurysms of the human brain treated with Guglielmi detachable coils. J Neurosurg. 1999; 91:284-293. [PubMed: 10433317]

8. Gallas S, Pasco A, Cottier JP, Gabrillargues J, Drouineau J, Cognard C, et al. A multicenter study of 705 ruptured intracranial aneurysms treated with Guglielmi detachable coils. Am J Neuroradiol. 2005; 26:1723-1731. [PubMed: 16091521]

9. Mericle RA, Wakhloo AK, Lopes DK, Lanzino G, Guterman LR, Hopkins N. Delayed aneurysm regrowth and recanalization after Guglielmi detachable coil treatment. J Neurosurg. 1998; 89:142145. [PubMed: 9647186]

10. Ford MD, Hoi Y, Piccinelli M, Antiga L, Steinman DA. An objective approach to digital removal of saccular aneurysms: technique and applications. Br J Radiol. 2009; 82:S55-61. [PubMed: 20348537] 


\section{A. Change in sac morphology during follow-up}

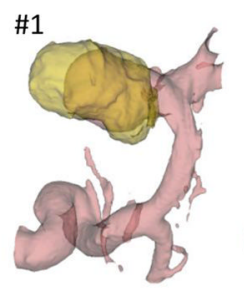

\#2

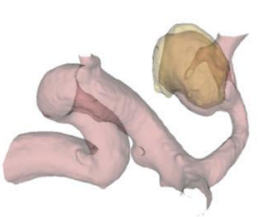

\#5

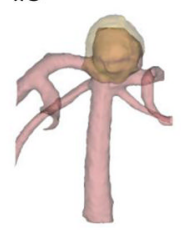

\#6

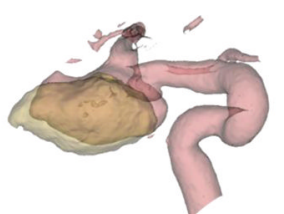

\#3

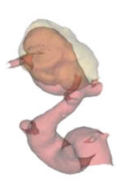

\#7

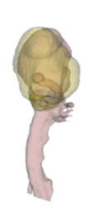

\#4

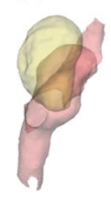

\#8

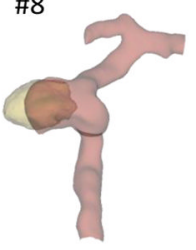

\#1

B. Change in coil mass morphology during follow-up

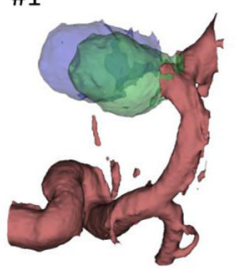

\#5

\#6

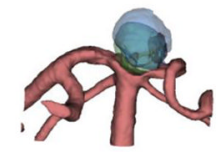

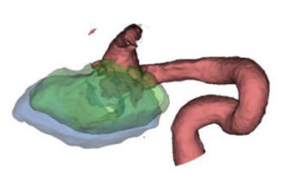

\#7

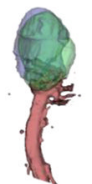

\#8

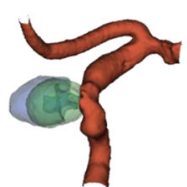

Figure 1.

(A) 3D models of the evolving aneurysm sac in study population. Initial aneurysm sac (prefirst treatment, pink shaded) is superimposed on that at followup (post-second treatment, yellow shaded). (B) 3D models of the evolving coil mass in study population. Initial coil mass (post-first treatment, green shaded) is superimposed on that at follow-up (pre-second treatment). Note that while all the sacs show some growth at follow-up, most coil mass has simply shifted at follow-up without compaction or major growth. Only a small portion of parent vessels is shown here although actual reconstructions included longer vessel segments to enable alignment (registration) of geometries. 
A

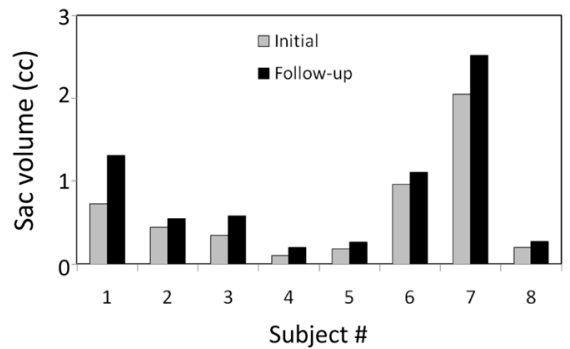

C

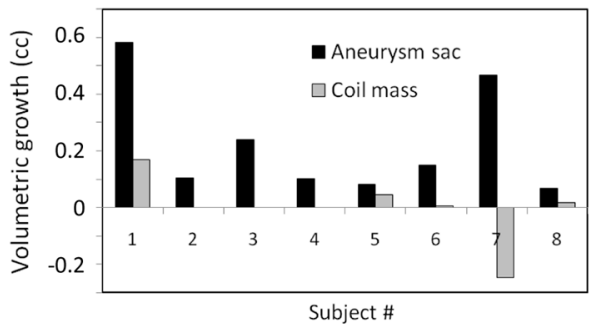

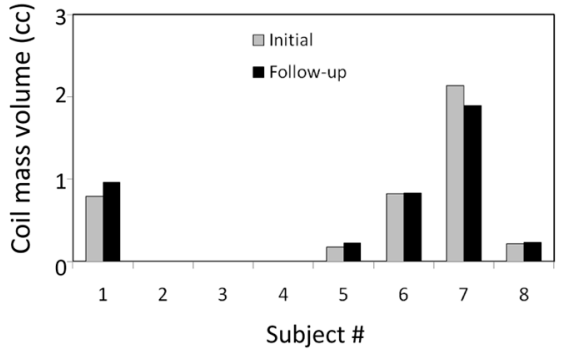

D

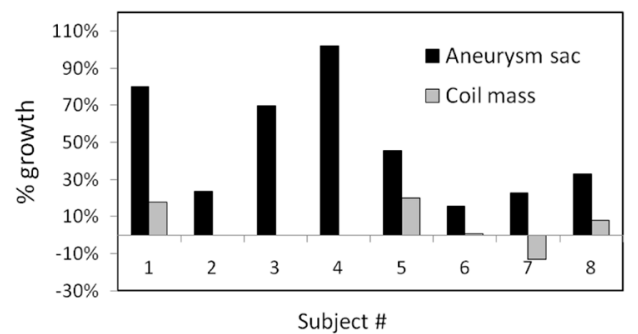

Figure 2.

Quantitative metrics on sac and coil mass changes. (A and B) Differences in volumes of aneurysm sac and coil mass between initial and follow-up period (A: $\boldsymbol{V}_{\mathrm{SI}}$ versus $\boldsymbol{V}_{\mathrm{SF}}$ for sac; B: $V_{\mathrm{CI}}$ versus $\boldsymbol{V}_{\mathrm{CF}}$ for coil). (C) Volumetric growth and (D) $\%$ volumetric growth in the aneurysm sac $\left(\boldsymbol{V}_{\mathrm{SG}}\right.$ and $\left.\% \boldsymbol{V}_{\mathrm{SG}}\right)$ and the coil mass $\left(\boldsymbol{V}_{\mathrm{CG}}\right.$ and $\left.\% \boldsymbol{V}_{\mathrm{CG}}\right)$ for study subjects. Substantive sac growth $\left(\boldsymbol{V}_{\mathrm{SG}}>0\right)$ may be seen in all subjects. Coil compaction $\left(\boldsymbol{V}_{\mathrm{CG}}<0\right)$ is observed only in one subject (\#7). 


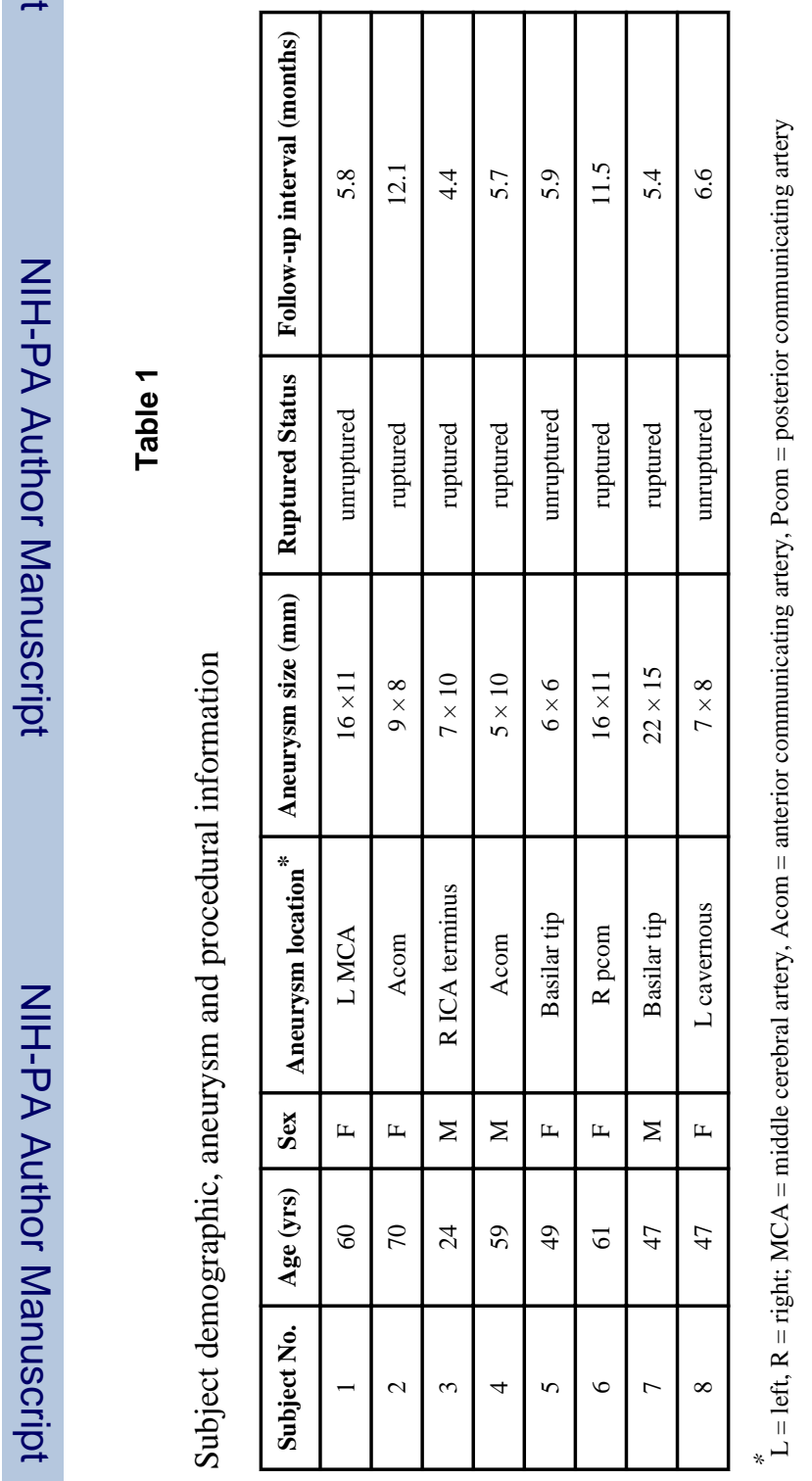

Stroke. Author manuscript; available in PMC 2013 March 01. 